\title{
Anemia in the frail, elderly patient
}

This article was published in the following Dove Press journal:

Clinical Interventions in Aging

17 March 2016

Number of times this article has been viewed

\author{
Gabriele Röhrig',2 \\ 'Ageing Clinical Research, \\ Department II of Internal Medicine, \\ University Hospital Cologne, \\ ${ }^{2}$ Department of Geriatrics, St Marien \\ Hospital Cologne, Cologne, Germany
}

\begin{abstract}
Anemia and frailty are two common findings in geriatric patients and have been shown to be associated with poor outcomes in this patient group. Recent studies have contributed to the growing evidence of a possible association with the age-related chronic inflammatory status known as "inflammaging". These findings do not only give a better insight into the pathogenesis of anemia in frailty, but also offer new treatment options. The present article focuses on this assumed association between anemia, frailty, and inflammaging and summarizes current management options for anemia in frail patients.
\end{abstract}

Keywords: anemia of chronic inflammation, frailty, inflammaging, eryptosis, reactive oxygen species

\section{Introduction}

With the rise of age in Western populations, health care systems and physicians will be increasingly confronted with special age-associated health conditions, comorbidities, and syndromes demanding different diagnostic and therapeutic approaches compared to younger patients. Anemia and frailty are two common syndromes in older patients, ${ }^{1}$ both describing a state of unphysiologic deficiency and imbalance: "anemia" derives from the Greek terms " $\alpha \nu$-", meaning "no", and "- $\alpha \mu \mu i ́ \alpha$ ", meaning "blood", describing a lack of red blood cells; "frailty" derives from the Latin term "fragilitas", meaning "ephemerality" and "weakness", indicating a state of vulnerability predisposing to adverse outcomes. ${ }^{1}$ Besides their association with advanced age, their increased prevalence among older people, and their association with functional decline and adverse outcomes, several recent studies have also revealed an association between anemia, frailty, and the age-associated state of chronic inflammation, based on immunosenescence. ${ }^{2-5}$ This process of "inflammaging" is characterized by an ageassociated chronic upregulation of the inflammatory immune response with increased levels of proinflammatory cytokines like interleukin-1 (IL-1), IL-6, and tumor necrosis factor (TNF). ${ }^{2,4}$ Inflammaging is believed to be a consequence of a lifetime exposure to antigenic load and environmental free radicals, resulting in a chronic proinflammatory state. ${ }^{4}$ The present article focuses on this association between anemia, frailty, and inflammaging.

\section{Anemia in the aged}

The term "anemia" describes a lack of red blood cells, associated with reduced levels of hematocrit and hemoglobin $(\mathrm{Hb})$. $\mathrm{Hb}$ is an iron-containing metalloprotein responsible for the physiologic transportation of oxygen inside the red blood cells throughout the human body. ${ }^{6}$ A lack of oxygen is known to be fatal for human organs and may cause malfunction and, if it persists, even organ failure. ${ }^{7}$ Anemia is therefore an unphysiologic state that has to be compensated. While anemic younger patients
Correspondence: Gabriele Röhrig

Ageing Clinical Research, Department II of Internal Medicine, University Hospital of Cologne, Herder Strasse 52 D-5093 I Cologne, Germany

Tel +49 22I 47886704

Fax +49 22I 478 86710

Email gabriele.roehrig@uk-koeln.de
Clinical Interventions in Aging 2016: | | 319-326

(c) (1) (2) ๑ 2016 Röhrig. This work is published and licensed by Dove Medical Press Limited. The full terms of this license are available at https://www.dovepress.com/terms.php cc. herbby accept the Terms. Non-commercial uses of the work are permitted without any further permisision from Dove Medical Press Limited, provided the work is properly atrtibuted. For permision for commercial use of this work, please see paragraphs 4.2 and 5 of our Terms (htpps://www.dovepress. com/terms.php).
Dovepress

http://dx.doi.org/10.2147/CIA.S90727 
may rely upon their organ reserves to compensate the lack of oxygen, anemic older patients $>65$ years appear rather disadvantaged on this point, because aging is associated with a progressive loss of functional organ reserves, increasing the risk of frailty. ${ }^{8}$

Anemia is a frequent finding in older patients and has been shown to be associated with increased physical impairment, ${ }^{9,10}$ frailty, ${ }^{11}$ cognitive decline, ${ }^{12}$ depression, ${ }^{13}$ and mortality. ${ }^{14}$ Several international studies have shown that the prevalence of anemia varies depending on the population considered: A study of the third National Health and Nutrition Examination Survey (NHANES III 1991-1994) showed an anemia prevalence of $>20 \%$ among communitydwelling seniors $>85$ years. ${ }^{15}$ A more recent study among Indian home-dwelling people was consistent with this finding, ${ }^{16}$ while a systematic review by Gaskell et al ${ }^{17}$ among geriatric inpatients $>65$ years living in developed countries found an anemia prevalence of up to $40 \%$. A large Austrian epidemiologic study showed a comparable prevalence of anemia among Austrian geriatric inpatients aged $\geq 90$ years. ${ }^{18}$ Our own research group found even higher prevalence rates of $>50 \%$ in German geriatric inpatients aged $\geq 70$ years, ${ }^{19,20}$ which is consistent with Spanish findings among geriatric inpatients. ${ }^{21}$ Preliminary results of the first German multicenter study on anemia prevalence among geriatric inpatients found a prevalence of $>55 \%$ and confirmed the previous findings of the monocentric studies. ${ }^{22}$

According to NHANES III, anemia can be roughly divided into three subtypes: anemias with nutrient deficiency like iron, folate, or vitamin B12 deficiency; anemias without nutrient deficiency like renal anemia (RA) or anemia of chronic inflammation (ACI); and anemias that cannot be classified and are therefore called "unexplained anemias" (UAs). ${ }^{15}$ Each of the subtypes formed one-third of all anemias in NHANES III. Results of the large Austrian epidemiologic study on older patients revealed ACI to be the most prevalent subtype with $62.1 \%{ }^{18}$ This finding was confirmed by the German multicenter study on anemia prevalence among geriatric inpatients. ${ }^{22}$

Anemia with nutrient deficiency is often associated with malnutrition, which is an important health-affecting factor among older patients. A review by Ahmed and Haboubi ${ }^{23}$ gives a broad insight into the age-associated biophysiological changes of the digestive system. Age-associated changes in the gastrointestinal tract as well as polymedication, depression, or social isolation are risk factors for malnutrition in older patients, ${ }^{23}$ resulting in anemia-relevant deficiency of micronutrients like iron, folic acid, vitamin B12, zinc, and copper. ${ }^{24}$
UA is considered an exclusion diagnosis due to lack of clear consensus on its clinical or experimental approach. Makipour et al reviewed a number of potential causes, including androgen insufficiency, stem cell aging, and myelodysplasia. ${ }^{25}$

ACI underlies the focus of the present review and will be the subject of the next section.

In most of the epidemiologic studies on anemia in the aged, WHO criteria are applied to define anemia with women being anemic if $\mathrm{Hb}<12 \mathrm{~g} / \mathrm{dL}$ and men being anemic if $\mathrm{Hb}<13 \mathrm{~g} / \mathrm{dL}$. However, the validity of these reference values for older patients, which were developed $>40$ years ago by a WHO expert group, ${ }^{26}$ is controversial. ${ }^{27-29}$ Several studies have shown that application of WHO criteria for anemia definition is not appropriate for aged patients. ${ }^{27,29}$ Not only was a reverse $\mathrm{J}$-shaped association between $\mathrm{Hb}$ and risk for all-cause mortality shown, ${ }^{27,28}$ but also an increasing mortality risk at elevated $\mathrm{Hb}$ levels. ${ }^{28}$ There is an ongoing quest for what can be considered a normal $\mathrm{Hb}$ reference value in older patients.

\section{Current insights into $\mathrm{ACl}$}

ACI, also known as anemia of chronic diseases, is the most common type of anemia in older patients. It is usually found in diseases associated with immune activation such as infections, autoimmune disorders, or age-associated inflammaging. ${ }^{30}$ The development of ACI is assumed to result from the interaction of several factors: iron retention in cells of the reticuloendothelial system (RES) makes the metal unavailable for erythropoiesis. This retention is mediated by inflammation-associated excessive elevation of the iron-regulatory peptide hepcidin, inhibiting the release of iron from RES cells. ${ }^{31}$ Hepcidin is responsible for the downregulation of the iron export protein ferroportin. Thus, iron remains "locked up" in the stores, resulting in a state of functional iron deficiency. Despite hepcidin-dependent iron limitation being considered to be the key factor in the development of ACI, the exact mechanisms underlying the blockade of erythropoiesis during inflammation are not well understood yet. Recent studies have focused on the bone marrow microenvironment, having a vital influence on the development of hematopoietic stem cells (HSCs). ${ }^{32}$ There is increasing knowledge that the cells of the bone marrow microenvironment produce factors and cytokines which are important for the self-renewal and survival of HSCs and that they can sense the hematopoietic needs of the organism, adapting the hematopoietic processes to the needs. Cells of the bone marrow microenvironment act as regulators of the 
hematopoietic differentiation, based on a complex interaction of cytokines. ${ }^{32}$ The release of inflammatory cytokines like IL-6, IL-1, TNF $\alpha$, and interferon $\gamma$ (IFN $\gamma$ ) triggers $\mathrm{ACI}^{33,34}$ by an increase of myelopoiesis at the expense of erythropoiesis, which is reduced and finally arrested. ${ }^{32}$ It is therefore assumed that systemic chronic inflammations may cause alterations in the bone marrow microenvironment, resulting in altered erythropoiesis. ${ }^{32}$

\section{Current aspects of frailty}

Results from recent studies increasingly suggest an association between immunosenescence, inflammation, and the development of frailty: The age-associated overall change of the immune system is called immunosenescence. According to Franceschi et al, ${ }^{35}$ inflammaging is part of the immunosenescence process, consisting of an age-associated upregulation of the inflammatory response, resulting in a lowgrade proinflammatory state. ${ }^{4}$ This proinflammatory state is characterized by increased levels of inflammatory cytokines, such as IL-6, IL-1, TNF $\alpha$, and IFN $\gamma$. These cytokines have been shown to rise with age ${ }^{36}$ and to be associated with the development of $\mathrm{ACI}^{32}$ and other age-associated diseases. ${ }^{37}$ The process of immunosenescence has been shown to result in increased vulnerability to infectious diseases as well as to susceptibility of inflammation-associated pathologies in connection with, eg, chronic kidney disease, cardiovascular disease, Alzheimer's disease, or diabetes mellitus. ${ }^{2,4,38}$ A study by Chang et $\mathrm{al}^{2}$ on the association between inflammatory disease burden and frailty revealed that a higher inflammatory disease count favors the occurrence of frailty in older patients. The consequence of the constant proinflammatory state does not only increase susceptibility to age-related diseases but also makes older patients prone to faster progression of all age-associated diseases.

Before realization of these biochemical insights into the pathogenesis of frailty, the syndrome of frailty experienced a more clinical approach. In the context of geriatrics, frailty describes a decline in physical strength, lean body mass, and power, associated with decreased balance, decreased walking performance, and low activity. ${ }^{39}$ Frailty has been associated with age for a very long time: The Shakespearean "shrunk shank" implies the age-associated loss of muscle mass or "sarcopenia". Frailty is considered to be a high risk state for adverse health outcomes. In 2001, Fried et al developed the first definition of frailty, based on the relationship between biologic and age-associated markers, linking in a cycle of frailty, spiraling down through sarcopenia, osteoporosis, and chronic undernutrition to reduced walking speed, weight loss, and finally immobility. ${ }^{39}$ Based on this finding, frailty is defined by the presence of three of the five "Fried criteria": exhaustion, weight loss, low activity, slow walking speed, and reduced grip strength. ${ }^{39}$ A state of pre-frailty is defined by the presence of one or two of the five criteria. ${ }^{39}$

Recent studies have revealed that additional factors increase the odds for being frail: Results of the San Antonio Longitudinal Study of Aging (SALSA) study showed that the ethnic composition and the economic environment of the neighborhoods of older Mexican Americans influence their chance to be frail. ${ }^{40}$ Similar findings were made by a French study group, underlining the adverse long-term effects of socioeconomic inequality over the lifetime of healthy aging older French individuals. ${ }^{41}$ A Spanish study group showed an association between frailty and impaired basic activities of daily living as well as mortality among institutionalized older adults. ${ }^{42}$ Frailty has been further shown to be associated with polymedication ${ }^{43}$ and poor postoperative outcome. ${ }^{44,45}$ The association with anemia will be discussed in the following paragraph.

\section{Association between anemia, frailty, and inflammaging}

Several studies have shown that anemia is associated with functional loss and poor outcome in older patients and has therefore been identified as an additional factor in the development of frailty. ${ }^{1,45,46}$ While the Fried criteria of frailty were based strictly on biological characteristics, ${ }^{39}$ the recently developed frailty index (FI) by $\mathrm{Ng}$ et $\mathrm{al}^{11}$ also includes socioeconomic and nutritional factors and comorbidities like anemia. ${ }^{11}$ Among the final 13 frailty predictors of the index were "low Hb" and "elevated white blood cell count (WBC)", implying the association between frailty, anemia, and inflammation. Indeed, in older patients, anemia and frailty have been shown to share a pathophysiology associated with chronic inflammatory processes, ${ }^{2,47}$ induced by immunosenescenceassociated changes ${ }^{4}$ and oxidative stress. ${ }^{47}$ Oxidative stress describes an imbalance between the physiologic oxidant and the antioxidant system of the human body, with prevalence of oxidants. Oxidants are physiologic products of the $\mathrm{O}_{2}$ energy metabolism, which can accumulate in certain disease conditions. ${ }^{47}$ The so-called "oxygen-free radicals" or reactive oxygen species (ROS) are extremely reactive molecules, causing harm by affecting cell membranes, proteins, enzymes, and DNA where they may alter genetic information. ${ }^{48} \mathrm{~A}$ recently published review by Barnes ${ }^{49}$ focused on the association between inflammaging, age-associated burden of diseases, 
and oxidative stress. Using the example of COPD, the author underlines the necessity of a multidimensional diagnostic and therapeutic approach based on the knowledge of the underlying molecular age-associated pathways.

Despite this growing awareness of a pathogenetic association between inflammaging, frailty, and anemia in older patients and the finding that anemia predisposes to a poorer disease outcome, ${ }^{50}$ until now a cause-and-effect relationship between anemia, frailty, and inflammation cannot be established.

A recent review by Wu et al gives an interesting insight into the intertwined association between frailty and inflammaging. The authors underline that aging is a process of deterioration and decline of physical strength, resulting from an individually different lifelong accumulation of intracellular and cellular damage, which may lead to systemic and organic failure.$^{51} \mathrm{At}$ the advanced stage, aging is associated with organ dysfunction, which might easily turn into organ failure in the presence of stress factors. Due to the individual heterogeneity of the aging process, physicians and health carers are in need of biomarkers, indicating the level of organ dysfunction. These biomarkers will allow an optimized prediction of morbidity, mortality, and adverse health outcome in every individual patient. Frailty has been shown to be such a biomarker, indicating that the aging process has reached the level of organ dysfunction if at least three of the five Fried criteria are met. ${ }^{39,51}$ Inflammaging, as a result of the age-associated immunosenescence, contributes to organ failure at the cellular level due to the associated increase of cytokines. These cytokines might also serve as biomarkers for the advanced aging process. Wu et al give a solid review of studies supporting the biomarking roles of cytokines as well as frailty in the individual health risk management of older patients..$^{51}$

As mentioned earlier, the pathogenetic association between ACI and inflammaging is based on increased levels of cytokines, possibly released by HSCs. However, until now, anemia has not been generally acknowledged as a biomarker for advanced age. A Spanish study group ${ }^{52}$ showed a significant association between the anemia-associated parameter red cell distribution width (RDW) and mortality, with RDW rising during the last 5 years of life. Elevated RDW levels, reflecting an increase of anisocytosis, have been shown to be associated with chronic diseases ${ }^{53}$ and chronic inflammation. ${ }^{54}$ The close relationship of anemia and anemia-associated parameters like RDW with inflammaging and frailty in older patients merits further research regarding their potential role as biomarkers.

\section{Is eryptosis a link?}

Erythrocyte suicidal death or eryptosis is a physiologic mechanism to remove defective erythrocytes from blood circulation. It is characterized by cell shrinkage and translocation of phosphatidylserine to the membrane surface, enabling phagocytes to engulf erythrocytes and eliminate them from circulation to prevent hemolysis..$^{55}$ In their very detailed review article, Lang and Lang described triggers of eryptosis, including oxidative stress and multimorbidity. ${ }^{55}$ Eryptosis was described in connection with several morbidities like diabetes mellitus, chronic heart disease, chronic renal insufficiency, and dehydration. ${ }^{55}$ A recent study by Pretorius et $\mathrm{al}^{56}$ focused on the association between eryptosis and the inflammatory signaling in Parkinson's disease (PD) based on the inflammatory cytokines involved in PD pathophysiology and eryptosis. They showed that erythrocytes of PD patients had a deranged morphology which might be due to eryptosis; ${ }^{56}$ however, causality could not be explained. An interesting recent study by Lupescu et $\mathrm{a}^{57}$ revealed a significant higher rate of phosphatidylserine presenting erythrocytes in older patients aged $88.6 \pm 0.9$ years than in younger patients aged $31.3 \pm 1.7$ years. ${ }^{57}$ The increase of phosphatidylserine exposition was paralleled by an increase of ROS, representing oxidative stress..$^{57}$ The authors concluded that anemia of the aged might be due to enhanced eryptosis. Bearing in mind the increased evidence of an association between aging and ROS and the finding of elevated levels of ROS in the heart ${ }^{58}$ and vasculature ${ }^{59}$ of aged patients and the assumed association of ROS with inflammaging, ${ }^{35}$ the conclusion by Lupescu et $\mathrm{al}^{57}$ sounds highly interesting. Besides the ROS triggers, Lang and Lang ${ }^{55}$ also listed several morbidities like diabetes mellitus, chronic heart disease, chronic renal insufficiency, and dehydration to be associated with eryptosis. ${ }^{55}$ These comorbidities are often seen in geriatric patients. In the study by Lupescu et al, seven patients suffered from diabetes mellitus, 14 from chronic kidney disease, and four from heart failure. ${ }^{57}$ These comorbidities might therefore also be held responsible for increased eryptosis. Although until now the exact underlying mechanisms are still unclear, one might assume a close connection between inflammaging, anemia, and frailty (Figure 1) with ROS in the center position, fed by comorbidities and inflammaging; ROS might cause eryptosis, the link to ACI, which has been shown to be the most frequent type of anemia in the aged. The final common path will lead to frailty (Figure 1). However, this hypothetical context remains to be proven. 


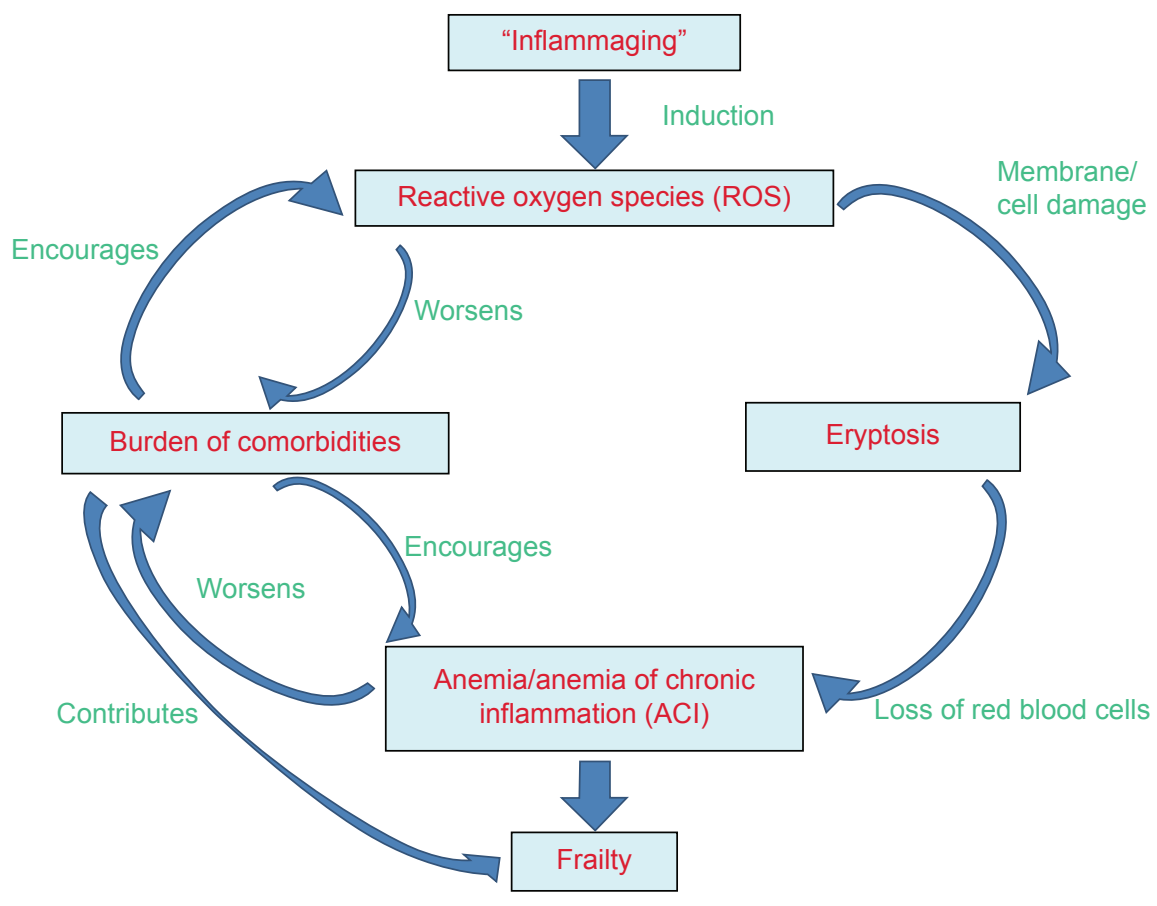

Figure I Hypothetical association between frailty, $\mathrm{ACl}$, and inflammaging.

\section{Management options for anemia in frail patients}

Despite the diverse causes for anemia in the aged, the lowest common denominator of iron deficiency anemia (IDA), ACI, or UA is iron deficiency, either absolute with empty iron stores like in IDA, or functional with the incapacity to release iron from the full iron stores like in ACI. Therefore, iron substitution is still the mostly recommended symptomatic treatment in IDA and $\mathrm{ACI}^{60}$ as well as in iron-deficient UA. ${ }^{61}$ Diagnosis and treatment of the underlying diseases are necessary in IDA and ACI, but interventions should always be adjusted to the individual geriatric patient's wish and prognosis in a harm-benefit balancing manner, based on comprehensive geriatric assessment results.

Oral iron substitution has been the gold standard in anemia treatment for decades. ${ }^{62}$ However, the discovery of hepcidin as a key factor in iron homeostasis ${ }^{63,64}$ and analysis of its role in connection with chronic inflammation ${ }^{64,65}$ revealed that hepcidin causes functional iron deficiency by binding to and degrading the iron export protein ferroportin. ${ }^{64}$ This leads to reduced enteral iron resorption and trapping of iron in macrophages and hepatocytes. ${ }^{65}$ In patients with ACI and inflammation-associated increase of hepcidin, oral iron substitution will therefore be ineffective and intravenous iron substitution is recommended. ${ }^{60}$ Several recent studies have shown that intravenous iron application is also safe in geriatric patients with chronic inflammation-associated anemia. ${ }^{66-68}$ Oral iron substitution is usually recommended in case of absolute iron deficiency. ${ }^{69}$ Results of a recent metaanalysis of oral iron substitution in older patients indirectly confirms this recommendation by revealing an increase of $\mathrm{Hb}$ after 4-6 weeks of oral iron substitution. ${ }^{70}$ However, a recent study by Silay et $\mathrm{al}^{71}$ raises doubts if this recommendation of oral iron substitution can be transferred to geriatric patients. In their cross-sectional study of 100 IDA patients divided into the age groups $\geq 65$ years and $<65$ years, they revealed a significantly lower iron absorption among older patients $\geq 65$ years compared to the younger patient group. A possible association with "inflammaging" 35,72 is speculative because underlying reasons remain subject to further research.

According to the transfusion guidelines of the German Medical Association, transfusion of red blood cells is usually indicated in case of severe, symptomatic anemia to prevent hypoxemia. ${ }^{73}$ A restrictive strategy is recommended in patients without cardiovascular diseases with erythrocyte transfusion only if $\mathrm{Hb}$ is $<6 \mathrm{~g} / \mathrm{dL} .^{73} \mathrm{~A}$ recent Danish study on erythrocyte transfusion in postoperative orthogeriatric hip fracture patients compared a restrictive $(\mathrm{Hb}<9.7 \mathrm{~g} / \mathrm{dL})$ with a liberal $(\mathrm{Hb}<11.3 \mathrm{~g} / \mathrm{dL})$ transfusion strategy. ${ }^{74}$ It revealed similar recovery of activities of daily living among the two study groups, but a significantly lower mortality rate in 
nursing home patients undergoing the liberal erythrocyte transfusion strategy. ${ }^{74}$ The fact that the $\mathrm{Hb}$ threshold of the restrictive strategy group was even above the threshold recommended by the German Medical Association underlines the urgent need for further research on transfusion strategies in geriatric patients to find the appropriate $\mathrm{Hb}$ thresholds.

Recent findings about the assumed interaction between immunosenescence and inflammaging, anemia of the aged, the importance of ROS, and the key enzyme of iron metabolism hepcidin have opened new research fields of therapeutic strategies. A very detailed review by Macciò and Madeddu ${ }^{47}$ focuses on the management of ACI in older patients. It highlights the current knowledge about hepcidinantagonizing agents in ACI to prevent iron trapping and the antagonization of the IL-6 pathway to lower hepcidin levels. ${ }^{47}$ They concede a potential beneficial effect to endogenous and exogenous antioxidants for the protection against oxidative damage caused by ROS, but also underline the lack of data to issue general recommendation. ${ }^{47}$

In conclusion, there is growing evidence of a close pathogenetic association between frailty, anemia of the aged, and inflammation, even though the underlying mechanisms still remain unclear. Further research on this field would contribute to new diagnostic and therapeutic strategies and might improve older patients' outcome.

\section{Disclosure}

The author reports no conflicts of interest in this work.

\section{References}

1. Artz AS. Anemia and the frail elderly. Semin Hematol. 2008;45(4): 261-266.

2. Chang SS, Weiss CO, Xue QL, Fried LP. Association between inflammatory-related disease burden and frailty: results from the Women's Health and Aging Studies (WHAS) I and II. Arch Gerontol Geriatr. 2012;54(1):9-15.

3. Leng S, Chaves P, Koenig K, Walston J. Serum interleukin-6 and hemoglobin as physiological correlates in the geriatric syndrome of frailty: a pilot study. J Am Geriatr Soc. 2002;50(7):1268-1271.

4. Baylis D, Bartlett DB, Patel HP, Roberts HC. Understanding how we age: insights into inflammaging. Longev Healthspan. 2013;2(1):8.

5. Bloomer SA, Kregel KC, Brown KE. Heat stress stimulates hepcidin mRNA expression and $\mathrm{C} / \mathrm{EBP} \alpha$ protein expression in aged rodent liver. Arch Gerontol Geriatr. 2014;58(1):145-152.

6. Shander A, Goodnough LT, Javidroozi M, et al. Iron deficiency anemia - bridging the knowledge and practice gap. Transfus Med Rev. 2014;28(3):156-166.

7. Ince C, Mik EG. Microcirculatory and mitochondrial hypoxia in sepsis, shock and resuscitation. J Appl Physiol (1985). 2016;120(2):226-235.

8. Alexa ID, Ilie AC, Moroşanu A, Voica A. Approaching frailty as the new geriatric syndrome. Rev Med Chir Soc Med Nat Iasi. 2013;117(3): 680-685.

9. Juárez-Cedillo T, Basurto-Acevedo L, Vega-García S, et al. Prevalence of anemia and its impact on the state of frailty in elderly people living in the community: SADEM study. Ann Hematol. 2014;93(12): 2057-2062.
10. Contreras M, Formiga F, Ferrer A, Chivite D, Padrós G, Montero A; Grupo Octabaix. Profile and prognosis of patients over 85 years old with anemia living in the community. Octabaix Study. Rev Esp Geriatr Gerontol. 2015;50(5):211-215.

11. Ng TP, Feng L, Nyunt MS, Larbi A, Yap KB. Frailty in older persons: multisystem risk factors and the Frailty Risk Index (FRI). J Am Med Dir Assoc. 2014;15(9):635-642.

12. Hong $\mathrm{CH}$, Falvey $\mathrm{C}$, Harris TB, et al. Anemia and risk of dementia in older adults: findings from the Health ABC study. Neurology. 2013; 81(6):528-533.

13. Son SJ, Lee KS, Na DL, et al. Anemia associated with depressive symptoms in mild cognitive impairment with severe white matter hyperintensities. J Geriatr Psychiatry Neurol. 2011;24(3):161-167.

14. Zakai NA, French B, Arnold AM, et al. Hemoglobin decline, function, and mortality in the elderly: the cardiovascular health study. Am J Hematol. 2013;88(1):5-9.

15. Guralnik JM, Eisenstaedt RS, Ferrucci L, Klein HG, Woodman RC. Prevalence of anemia in persons 65 years and older in the United States: evidence for a high rate of unexplained anemia. Blood. 2004;104(8): 2263-2268.

16. Paul SS, Abraham VJ. How healthy is our geriatric population? A community-based cross-sectional study. J Family Med Prim Care. 2015;4(2):221-225.

17. Gaskell H, Derry S, Andrew Moore R, McQuay HJ. Prevalence of anaemia in older persons: systematic review. BMC Geriatr. 2008; 14(8):1.

18. Bach V, Schruckmayer G, Sam I, Kemmler G, Stauder R. Prevalence and possible causes of anemia in the elderly: a cross-sectional analysis of a large European university hospital cohort. Clin Interv Aging. 2014; 22(9):1187-1196.

19. Zilinski J, Zillmann R, Becker I, Benzing T, Schulz RJ, Röhrig G. Prevalence of anemia among elderly inpatients and its association with multidimensional loss of function. Ann Hematol. 2014;93(10): $1645-1654$

20. Röhrig G, Klossok W, Becker I, Benzing T, Schulz RJ. Prevalence of anemia among elderly patients in an emergency room setting. Eur Geriatr Med. 2014;5(1):3-7.

21. Romero-Ruperto S, Pérez-Bocanegra MC, Duran-Taberna M, ToscanoRivera A, Barbé-Gil Ortega J, San José-Laporte A. Anemia in elderly patients admitted to an acute geriatric ward. Rev Esp Geriatr Gerontol. 2015;50(3):122-125.

22. Röhrig G, Rücker Y, Becker I, et al. Association of anemia with functional and nutritional status in the German multicenter study “GeriAnaemie2013”. Z Gerontol Geriatr. 2015;48(S1):S14-S02. German.

23. Ahmed T, Haboubi N. Assessment and management of nutrition in older people and its importance to health. Clin Interv Aging. 2010;5: 207-216.

24. Chan LN, Mike LA. The science and practice of micronutrient supplementations in nutritional anemia: an evidence-based review. JPEN J Parenter Enteral Nutr. 2014;38(6):656-672.

25. Makipour S, Kanapuru B, Ershler WB. Unexplained anemia in the elderly. Semin Hematol. 2008;45(4):250-254.

26. World Health Organization. Nutritional anaemias. Report of a WHO scientific group. World Health Organ Tech Rep Ser. 1968;405:5-37.

27. Zakai NA, Katz R, Hirsch C, et al. A prospective study of anemia status, hemoglobin concentration, and mortality in an elderly cohort: the Cardiovascular Health Study. Arch Intern Med. 2005;165(19): 2214-2220.

28. Culleton BF, Manns BJ, Zhang J, Tonelli M, Klarenbach S, Hemmelgarn BR. Impact of anemia on hospitalization and mortality in older adults. Blood. 2006;107(10):3841-3846.

29. Beutler E, Waalen J. The definition of anemia: what is the lower limit of normal of the blood hemoglobin concentration? Blood. 2006; 107(5):1747-1750.

30. Hunt KJ, Walsh BM, Voegeli D, Roberts HC. Inflammation in aging part 2: implications for the health of older people and recommendations for nursing practice. Biol Res Nurs. 2010;11(3):253-260. 
31. Theurl I, Schroll A, Sonnweber T, et al. Pharmacologic inhibition of hepcidin expression reverses anemia of chronic inflammation in rats. Blood. 2011;118(18):4977-4984.

32. Gomes AC, Gomes MS. Hematopoietic niches, erythropoiesis and anemia of chronic infection. Exp Hematol. Epub 2015 Nov 22.

33. Libregts SF, Gutiérrez L, de Bruin AM, et al. Chronic IFN- $\gamma$ production in mice induces anemia by reducing erythrocyte life span and inhibiting erythropoiesis through an IRF-1/PU.1 axis. Blood. 2011;118(9):2578-2588.

34. Felli N, Pedini F, Zeuner A, et al. Multiple members of the TNF superfamily contribute to IFN-gamma-mediated inhibition of erythropoiesis. J Immunol. 2005;175(3):1464-1472.

35. Franceschi $\mathrm{C}$, Bonafè $\mathrm{M}$, Valensin $\mathrm{S}$, et al. Inflamm-aging. An evolutionary perspective on immunosenescence. Ann N Y Acad Sci. 2000; 908:244-254.

36. Vasto S, Candore G, Balistreri CR, et al. Inflammatory networks in ageing, age-related diseases and longevity. Mech Ageing Dev. 2007; 128(1):83-91.

37. De Martinis M, Franceschi C, Monti D, Ginaldi L. Inflammation markers predicting frailty and mortality in the elderly. Exp Mol Pathol. 2006;80(3):219-227.

38. Weiskopf D, Weinberger B, Grubeck-Loebenstein B. The aging of the immune system. Transpl Int. 2009;22(11):1041-1050.

39. Fried LP, Tangen CM, Walston J, et al; Cardiovascular Health Study Collaborative Research Group. Frailty in older adults: evidence for a phenotype. J Gerontol A Biol Sci Med Sci. 2001;56(3):M146-M156.

40. Espinoza SE, Hazuda HP. Frailty prevalence and neighborhood residence in older Mexican Americans: the San Antonio longitudinal study of aging. J Am Geriatr Soc. 2015;63(1):106-111.

41. Herr M, Robine JM, Aegerter P, Arvieu JJ, Ankri J. Contribution of socioeconomic position over life to frailty differences in old age: comparison of life-course models in a French sample of 2,350 old people. Ann Epidemiol. 2015;25(9):674-680.e1.

42. de la Rica-Escuín M, González-Vaca J, Varela-Pérez R, et al. Frailty and mortality or incident disability in institutionalized older adults: the FINAL study. Maturitas. 2014;78(4):329-334.

43. Runganga M, Peel NM, Hubbard RE. Multiple medication use in older patients in post-acute transitional care: a prospective cohort study. Clin Interv Aging. 2014;2(9):1453-1462.

44. Ambler GK, Brooks DE, Al Zuhir N, et al. Effect of frailty on shortand mid-term outcomes in vascular surgical patients. $\mathrm{Br} J$ Surg. 2015;102(6):638-645.

45. Kim SW, Han HS, Jung HW, et al. Multidimensional frailty score for the prediction of postoperative mortality risk. JAMA Surg. 2014;149(7): 633-640

46. Silva JC, Moraes ZV, Silva C, et al. Understanding red blood cell parameters in the context of the frailty phenotype: interpretations of the FIBRA (Frailty in Brazilian Seniors) study. Arch Gerontol Geriatr. 2014;59(3):636-641.

47. Macciò A, Madeddu C. Management of anemia of inflammation in the elderly. Anemia. 2012;2012:563251.

48. Azzi A, Davies KJA, Kelly F. Free radical biology - terminology and critical thinking. FEBS Lett. 2004;558(1-3):3-6.

49. Barnes PJ. Mechanisms of development of multimorbidity in the elderly. Eur Respir J. 2015;45(3):790-806.

50. Okafor UH, Unuigbe EI. Cardio-renal-anemia syndrome: a report of three cases. Saudi J Kidney Dis Transpl. 2012;23(3):562-568.

51. Wu IC, Lin CC, Hsiung CA. Emerging roles of frailty and inflammaging in risk assessment of age-related chronic diseases in older adults: the intersection between aging biology and personalized medicine. Biomedicine (Taipei). 2015;5(1):1.

52. Martínez-Velilla N, Cambra-Contin K, García-Baztán A, AlonsoRenedo J, Herce PA, Ibáñez-Beroiz B. Change in red blood cell distribution width during the last years of life in geriatric patients. J Nutr Health Aging. 2015;19(5):590-594.

53. Patel KV, Semba RD, Ferrucci L, et al. Red cell distribution width and mortality in older adults: a meta-analysis. J Gerontol A Biol Sci Med Sci. 2010;65(3):258-265.
54. Hu D, Ren J, Wang G, Gu G, Li G, Liu S. Value of red cell distribution width for assessing disease activity in Crohn's disease. Am J Med Sci. 2015;349(1):42-45.

55. Lang E, Lang F. Triggers, inhibitors, mechanisms, and significance of eryptosis: the suicidal erythrocyte death. Biomed Res Int. 2015; 2015:513-518.

56. Pretorius E, Swanepoel AC, Buys AV, Vermeulen N, Duim W, Kell DB. Eryptosis as a marker of Parkinson's disease. Aging (Albany NY). 2014; 6(10):788-819.

57. Lupescu A, Bissinger R, Goebel T, et al. Enhanced suicidal erythrocyte death contributing to anemia in the elderly. Cell Physiol Biochem. 2015;36(2):773-783.

58. Judge S, Young MJ, Smith A, Hagen T, Leeuwenburgh C. Age-associated increases in oxidative stress and antioxidant enzyme activities in cardiac interfibrillar mitochondria: implications for the mitochondrial theory of aging. FASEB J. 2005;19(3):419-421.

59. Ungvari Z, Orosz Z, Labinskyy N, et al. Increased mitochondrial H2O2 production promotes endothelial NF- $\mathrm{KB}$ activation in aged rat arteries Am J Physiol Heart Circ Physiol. 2007;293(1):H37-H47.

60. Metzgeroth $\mathrm{G}$, Hastka J. Iron deficiency anemia and anemia of chronic disorders. Internist (Berl). 2015;56(9):978-988.

61. Dahlerup JF, Eivindson M, Jacobsen BA, et al. Diagnosis and treatment of unexplained anemia with iron deficiency without overt bleeding. Dan Med J. 2015;62(4):C5072.

62. Poetes J. Oral iron therapy in hemorrhagic, infectious and tumorous anemias. Hippokrates. 1954;25(20):651-652.

63. Kulaksiz H, Theilig F, Bachmann S, et al. The iron-regulatory peptide hormone hepcidin: expression and cellular localization in the mammalian kidney. J Endocrinol. 2005;184(2):361-370.

64. Nemeth E, Valore EV, Territo M, Schiller G, Lichtenstein A, Ganz T. Hepcidin, a putative mediator of anemia of inflammation, is a type II acute-phase protein. Blood. 2003;101(7):2461-2463.

65. Gangat N, Wolanskyj AP. Anemia of chronic disease. Semin Hematol. 2013;50(3):232-238.

66. Bach M, Geisel T, Martin J, et al. Efficacy and safety of intravenous ferric carboxymaltose in geriatric inpatients at a German tertiary university teaching hospital: a retrospective observational cohort study of clinical practice. Anemia. 2015;2015:647930.

67. Röhrig G, Steinmetz T, Stein J, et al. Efficacy and tolerability of ferric carboxymaltose in geriatric patients with anemia. Data from three non-interventional studies. MMW Fortschr Med. 2014;156(Suppl 2): 48-53.

68. Reed J, Charytan C, Yee J. The safety of intravenous iron sucrose use in the elderly patient. Consult Pharm. 2007;22(3):230-238.

69. Hastka J, Heimpel H, Metzgeroth G. Eisenmangel und Eisenmangelanämie [Onkopedia guideline]. Available from: https://www.onkopedia. com/de/onkopedia/guidelines/eisenmangel-und-eisenmangelanaemie. Accessed October 23, 2015. German.

70. Tay HS, Soiza RL. Systematic review and meta-analysis: what is the evidence for oral iron supplementation in treating anaemia in elderly people? Drugs Aging. 2015;32(2):149-158.

71. Silay K, Akinci S, Yalcin A, et al. The status of iron absorption in older patients with iron deficiency anemia. Eur Rev Med Pharmacol Sci. 2015; 19(17):3142-3145.

72. Franceschi C, Campisi J. Chronic inflammation (inflammaging) and its potential contribution to age-associated diseases. J Gerontol A Biol Sci Med Sci. 2014;69(Suppl 1):S4-S9.

73. German Medical Association. (Bundesärztekammer): Guidelines of the German Medical Association for Therapy with Blood Components and Plasma Derivatives. 4th revised edition, German Medical Publishers (Deutscher Ärzte Verlag); 2014: Chapters 1, 10-19. German.

74. Gregersen M, Borris LC, Damsgaard EM. Blood transfusion and overall quality of life after hip fracture in frail elderly patients - the transfusion requirements in frail elderly randomized controlled trial. J Am Med Dir Assoc. 2015;16(9):762-766. 


\section{Publish your work in this journal}

Clinical Interventions in Aging is an international, peer-reviewed journal focusing on evidence-based reports on the value or lack thereof of treatments intended to prevent or delay the onset of maladaptive correlates of aging in human beings. This journal is indexed on PubMed Central, MedLine,

CAS, Scopus and the Elsevier Bibliographic databases. The manuscript management system is completely online and includes a very quick and fair peer-review system, which is all easy to use. Visit http://www.dovepress. com/testimonials.php to read real quotes from published authors.

Submit your manuscript here: http://www.dovepress.com/clinical-interventions-in-aging-journal 